\title{
Assessment of Acoustical Indicators in Multi-domed Historic Structures by Non-exponential Energy Decay Analysis
}

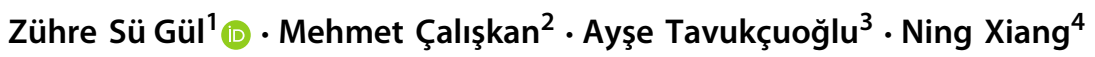

Received: 19 February 2018 / Accepted: 16 June 2018 / Published online: 25 June 2018

(c) Australian Acoustical Society 2018

\begin{abstract}
The key concern of this study is to discuss the reliable acoustical metrics for analyzing particular sound fields within monumental multi-domed sacred spaces with an emphasis on multiple sound energy decay formation. The potential of such structures in featuring non-exponential sound energy decay characteristics necessitates new formulation of sound decay indicators in understanding of their sound fields. The early and late energy decay components within non-exponential sound energy decays can have a unique contribution to the interior acoustic quality. These acoustical features can also provide the functional and spiritual acoustical needs of monumental sacred spaces. Süleymaniye Mosque and Hagia Sophia, two major monuments of Istanbul World Heritage Site, are examined in this regard. Field measurements are the main method of data collection. Over collected room impulse responses, relevant acoustical predictors including decay rates and decay times are computed by applying Bayesian decay parameter estimation. Analysis results disclose double or triple decay formations in both structures. Authors argue that, the detection of multiple sound energy decays in analyzed structures sets out a new vision for room acoustics studies of sacred spaces and for multi-domed monuments. Thus, implementation of new metrics, namely multiple slope decay parameters to replace classical room acoustics indicators, is recommended and discussed in light of the outcomes of this study.
\end{abstract}

Keywords Acoustical indicators · Multiple sound energy decay $\cdot$ Bayesian analysis · Sacred space acoustics $\cdot$ Süleymaniye Mosque $\cdot$ Hagia Sophia in İstanbul

\section{Introduction}

This research investigates the exceptional or uncommon sound fields within monumental sacred structures with an emphasis on multiple sound energy decay formation and proposes reliable acoustical metrics in their assessment. From a broader standpoint, the study concerns the intersection level of two crucial research grounds, namely "monumental

Zühre Sü Gül

zuhre@bilkent.edu.tr

1 Department of Architecture, Bilkent University, 06800 Ankara, Turkey

2 Department of Mechanical Engineering, Middle East Technical University, 06800 Ankara, Turkey

3 Department of Architecture, Middle East Technical University, 06800 Ankara, Turkey

4 Graduate Program in Architectural Acoustics, School of Architecture, Rensselaer Polytechnic Institute, Troy, NY 12180, USA sacred spaces" and "virtually coupled spaces." The superstructures of such monumental structures composed of one main dome coupled with sub-domes have potential to feature non-exponential sound energy decay characteristics. Those characteristics necessitate new formulation of sound decay indicators to better understand and better define their sound fields.

Main architectural features of such spaces are their excessive volumes and multi-domed upper shell typology in the form of main dome spaces coupled to sub-dome spaces $[1,2]$. An important discussion point is that such sacred monuments provide not a single decay with a single reverberation time but multiple sound energy decays, which are rarely observed in modest-sized single-space structures. Geometrical features and interior material attributes of these structures enhance the potential of non-exponential sound energy decay formation. Thus, it necessitates a further understanding of their interior acoustical quality by utilizing applicable acoustical indicators. 
In that respect, the interior sound fields of Süleymaniye Mosque and Hagia Sophia in İstanbul are examined. Their historical significance as of being cultural heritages and religious use has previously motivated many researchers to test their interior sound quality [3-6]. This research takes the earlier classical room acoustics parameter estimations a step forward. In this study, the acoustical analysis does not rely on conventional reverberation time estimations using single sound energy decay curves. But instead, the study aims to identify and quantitatively assess the effects of the multiple sound energy decays in such mega-structures. The basic methodology of multiple sound energy decay investigations used in this study is decay parameter estimations that rely on Bayesian formulation [7], over collected field measurement data.

The basic challenge in acoustical design of sacred spaces is optimizing reverberance versus intelligibility. It is well known that very high reverberation negatively affects speech intelligibility, while very short reverberation causes a dry acoustical environment that would reduce the envelopment and spaciousness in a religious space. These two contradictory requirements, namely clarity and reverberance, are difficult to be satisfied with classical sound energy decay properties of a single-space room. On the other hand, nonexponential energy or multiple decay regarding to its inherent properties of early and late decays can maintain the sense of intimacy and clarity that is mostly observed in coupled spaces. Specific combinations of different architectural volumes are highly correlated with room acoustics coupling. Multi-domed monumental structures have potential for featuring multi-slope sound energy decays.

In the literature, most of the investigations on sacred spaces have concentrated on the behavior of sound within different building typologies, as of churches $[8,9]$ or mosques $[10,11]$, their comparison and corresponding acoustical criteria [12-14]. Mostly, the sound field investigations in such sacred structures rely on a single sound energy decay and considers the first 20 or $30 \mathrm{~dB}$ linear decay of the slope for defining reverberation time. On the other hand, "room acoustics coupling" has far been investigated for theoretical understanding of convex (non-exponential) sound energy decay characteristics mostly in coupled spaces [15-17]. For this research, it is motivational that convex decay curve which incorporates multiple decays is previously observed in large cathedrals or basilicas, which are composed of interconnected subspaces [18-22].

Considering all, this study involves a comprehensive comparative analysis of multiple decay curves within single spaces of two monumental multi-domed cultural heritages. The paper discusses the particular sound fields of the two monuments in relation to their geometrical and material attributes. The significance of multiple decay, in the form of early and late energy for providing the spiritual needs of sacred spaces is highlighted, and the acoustical metrics to define the sound fields in superstructures are revisited.

\section{Structures Under Investigation: Süleymaniye Mosque and Hagia Sophia}

Being the largest of the Ottoman building enterprises of the time, Süleymaniye Mosque and Complex (1550-1557) is sponsored by Süleyman the Magnificent in his ruling and designed by "Sinan the Architect." Süleymaniye Mosque is the central figure of the complex (Fig. 1) and has always been an inspiration source for many fields including architectural aesthetics, structure and construction, acoustics and material science. The acoustics of the mosque, in this respect, is an important subject of research.

The inner plan of the mosque is measuring approximately $63 \mathrm{~m}$ by $69 \mathrm{~m}$. The upper structure is composed of a centralmain dome, supported on two sides by semidomes. There are smaller domes above side aisles and transitional elements as of muqarnas and pendentives. Elephant feet, arches and columns are load-bearing elements. Main dome has a diameter of $26.20 \mathrm{~m}$. The height of the main dome from the ground

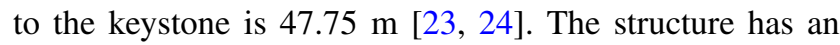
acoustical interior volume roughly around $100,000 \mathrm{~m}^{3}$.

The interior walls of Süleymaniye Mosque are clad with stone facings, out of marble and limestone. Brick dome masonry is painted and then decorated with gold-foiled pen paintings [25]. Floor finish of the mosque is carpet. The Mosque has undergone many restoration works in its life span. There have been replacements on interior finish plasters, while major structural and spatial characteristics are kept as in its original. Its existing sound field can be best assessed through real-size field measurements.

Hagia Sophia, on the other side, is constructed as a church in İstanbul (Constantinople) in the ruling of Justinian-the emperor of Byzantine (532-537). After the Ottoman conquest in 1453, it was converted from church to mosque. Upon an initiative from Mustafa Kemal Atatürk, founder of Turkish Republic, Hagia Sophia has been functioning as a museum since 1932 and is still one of the most inspiring architectural achievements of all time (Fig. 2). Over the 1400 years of its existence, Hagia Sophia has suffered much damage essentially due to major earthquakes. It has also undergone many alterations due to changes in its activity patterns [26]. As Hagia Sophia ended up to be a museum, initially all the carpets on the floor have been removed. In 1992, a major restoration and consolidation of the mosaics in the dome was started by the Central Laboratory for Restoration and Conservation of İstanbul in collaboration with UNESCO.

As of today, the major figure of Hagia Sophia is an expanded dome basilica with an interior length of $73.50 \mathrm{~m}$ and a width of $69.50 \mathrm{~m}$, excluding the narthex and the apse. 

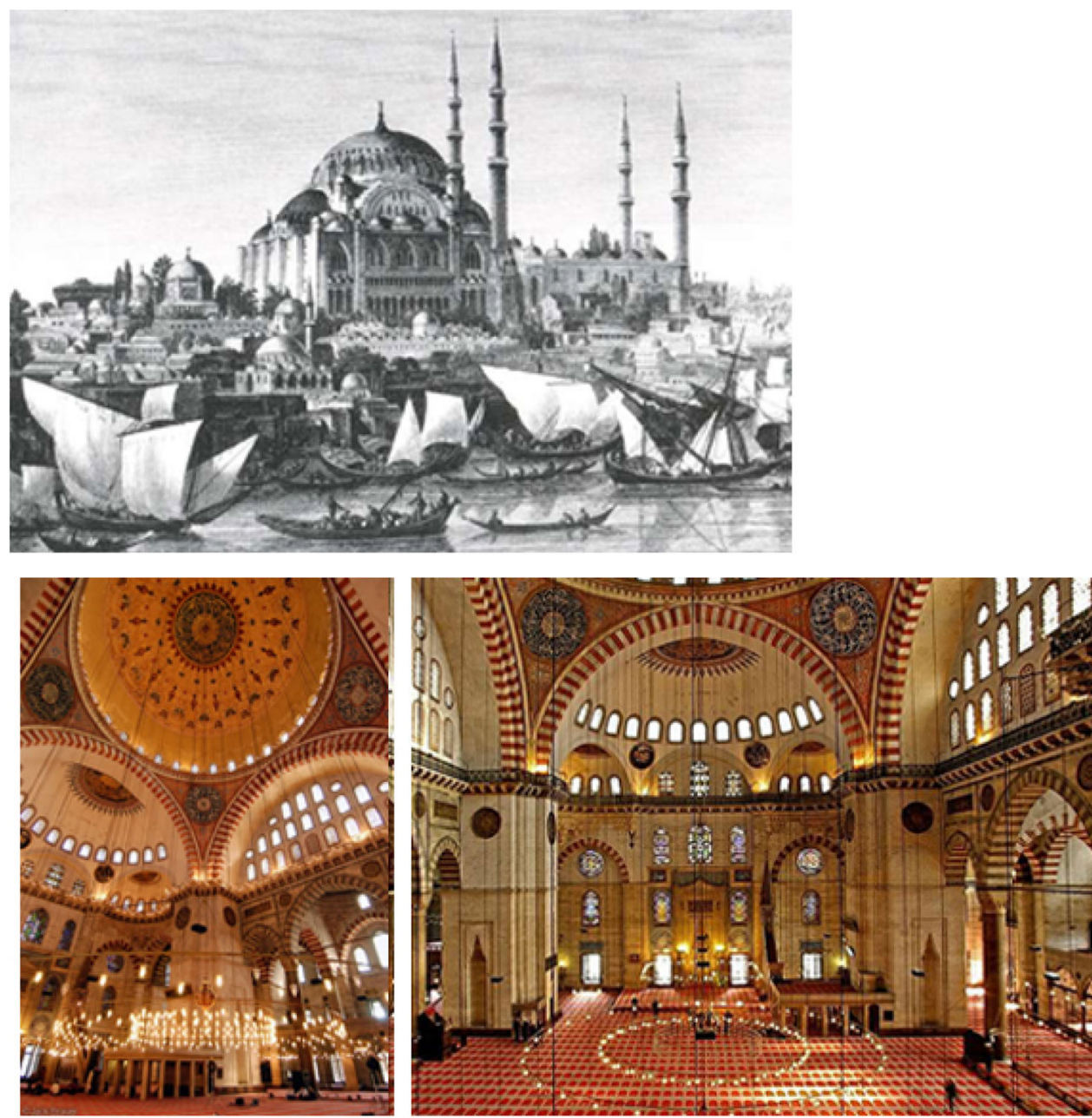

Fig. 1 Süleymaniye complex —an old gravure (Source: anonymous) and interior views
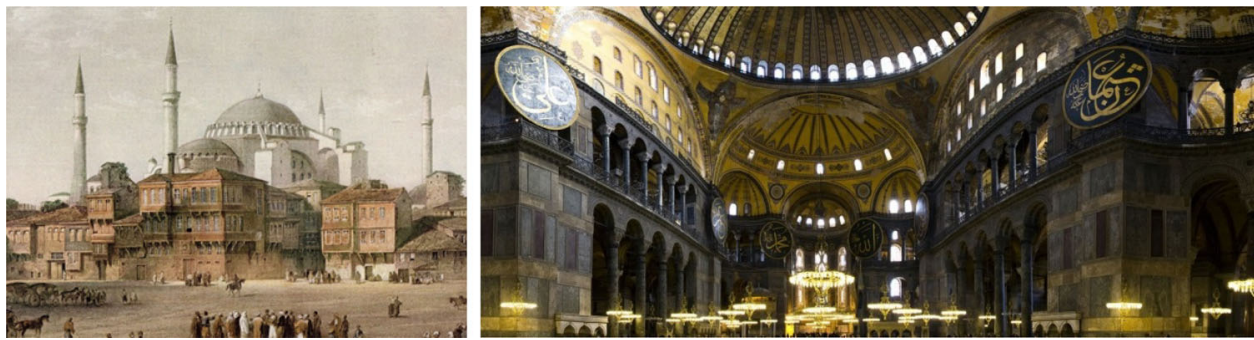

Fig. 2 Hagia Sophia—an old painting [22: p. 250] and interior view. (ayasofyamuzesi.gov.tr)

Rectangular plan is sheltered by a central dome between two half domes. The central—slightly elliptical—dome has a diameter of $31.25 \mathrm{~m}$ on one axis and $32.80 \mathrm{~m}$ on the other, and rises $55 \mathrm{~m}$ above the pavement of the nave. In between main piers and arches of the main space, pendentives are utilized. Columns, smaller arches and vaults are the major structural elements of side aisles [27]. With an approximate inner volume of $200,000 \mathrm{~m}^{3}$, Hagia Sophia has an outstanding visual and acoustical environment.
Brick and stone-limestone, marble and granite-are the major materials applied for the above-ground structure of Hagia Sophia. Most of the original marble revetments on walls and original non-figural mosaic decorations on vaults remain undamaged at ground level. Tesserae cut from natural stones, and terracotta are used in some of the non-figural decoration over the galleries. Today, the original floor pavement crushed in 1346 has been replaced with large rectangular marble slabs [27]. Volume-sub-volume interactions, sizes 


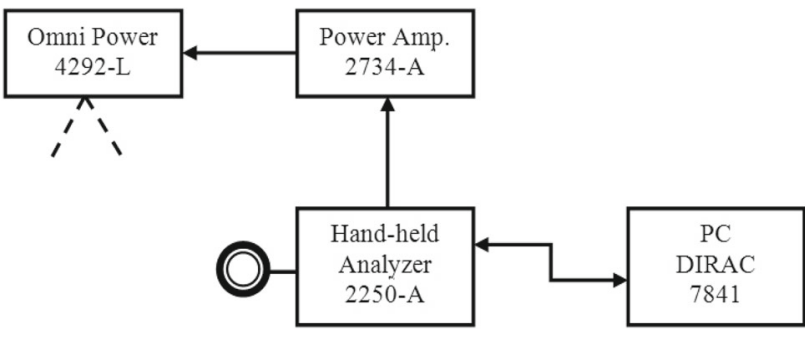

Fig. 3 Measurement setup of field tests. Source: produced by the author

and main geometrical features of the enclosures, physical and acoustical properties of interior surface materials and their distribution are all significant aspects shaping the interior sound fields of Süleymaniye Mosque and Hagia Sophia.

\section{Methodology}

\subsection{Field Measurements}

Field tests were held in Süleymaniye Mosque on February 23, 2013, hours in between 19:30 (p.m.) and 3:00 (a.m.) [2] at the main prayer hall, and in Hagia Sophia on August 25, 2014, hours in between 09.00 (a.m.) and 12.00 (a.m.) at ground floor, for both in unoccupied conditions. Measurement system includes B\&K (Type 4292-L) standard dodecahedron omni-power sound source, B\&K (Type 2734-A) power amplifier and B\&K (Type 4190ZC0032) microphone (Fig. 3) covering the frequency interval in between 100 and $8000 \mathrm{~Hz}$. Sampling frequency of the recorded multi-spectrum impulse is $48 \mathrm{kHz}$. DIRAC Room Acoustics Software Type 7841 v.4.1 is used for signal generation and post-processing.

For reliable decay parameter estimations, it is aimed to get signal that is at least $50 \mathrm{~dB}$ higher than the noise in all octaves (peak-to-noise ratio-PNR $>50 \mathrm{~dB}$ ). Tested signals are e-sweep, MLS, MLSpink, balloon pop and wood clap. Maximum 5 pre-averages are applied over multiple measurements, with impulse response length of $21.8 \mathrm{~s}$. The reason for testing different source signals is to identify the type that provides highest PNR values throughout the frequency spectrum. High PNR values are directly related to multi-slope detection in a decay curve.

Effects of spatial variations on multi-slope decay formation are searched over impulse responses obtained at different source and receiver combinations. Ray tracing simulations held before field tests are utilized in estimating probable strong coupling configurations. Considering the time limitations within the given permission of entrance to the historically significant case structures, maximum number of measurements are aimed to be held for critical source-receiver locations.
Two major source locations in Süleymaniye Mosque are designated as the one in front of mihrab (S1) and the other at müezzin mahfili (S3) (Fig. 4, on the left). The positioning of sound source is important to assess the acoustics of mosque for its traditional use. For acoustical coupling or multi-decay rate investigation, additional source locations such as one underneath the main dome (S4) and one underneath side corner dome (S2) are tested. Eight receiver locations (R1-R8) are coupled with four source locations (S1-S4) providing measured source-receiver configurations. In order to compare multi-slope decay formation for different locations considering the effects of spatial variations (such as main central space versus underneath side galleries) within Hagia Sophia, three source (S1-S3) and six receiver (R1-R6) positions are tested in various configurations (Fig. 4, on the right). Room impulse responses measured on site are then computed by Bayesian probabilistic inference method for multiple sound energy decay analysis.

\subsection{Decay Parameter Estimations by Bayesian Formulation}

Decay rate and decay order estimations of multiple slopes have always been a challenging task. Researchers have proposed different methods for identifying double-slope decays and the degree of coupling. Visual inspection, comparisons of linear-fits of different portions of logarithmic decay functions or applying ratio-based quantifiers without considering their absolute values are proved to be scientifically ineffective especially when the decay profile has more than two slopes.

The computational analysis methodology of this study employs Bayesian probabilistic inference as an efficient tool. Bayesian analysis has recently been applied in several studies, and reliable methods in characterizing sound energy decays consisting of one or two slopes have been presented $[7,28-30]$. Bayesian probability theory is a quantitative theory of inference that includes valid rules of statistics for relating and manipulating probabilities. It considers all the given information on the data input and determines local extremes. The parameters that are out of interest can be incorporated and averaged over or marginalized. Marginalization reduces the dimensionality of the parameter space enabling a better handling of the parameter [7].

The computational analysis method starts with data collection in the form of impulse responses. Out of these collected sound files, energy decay curves can be obtained. Schroeder's backward integration, which defines Schroeder decay function, is also the essence of reverberation time calculations. It gives a smoother shape to the energy decay curves, making it easier and reliable to compute many other objective acoustical parameters. Bayesian model-based parameter estimation, relying on the model approximation of real-data out of Schroeder curve, is used to produce an algorithm for 

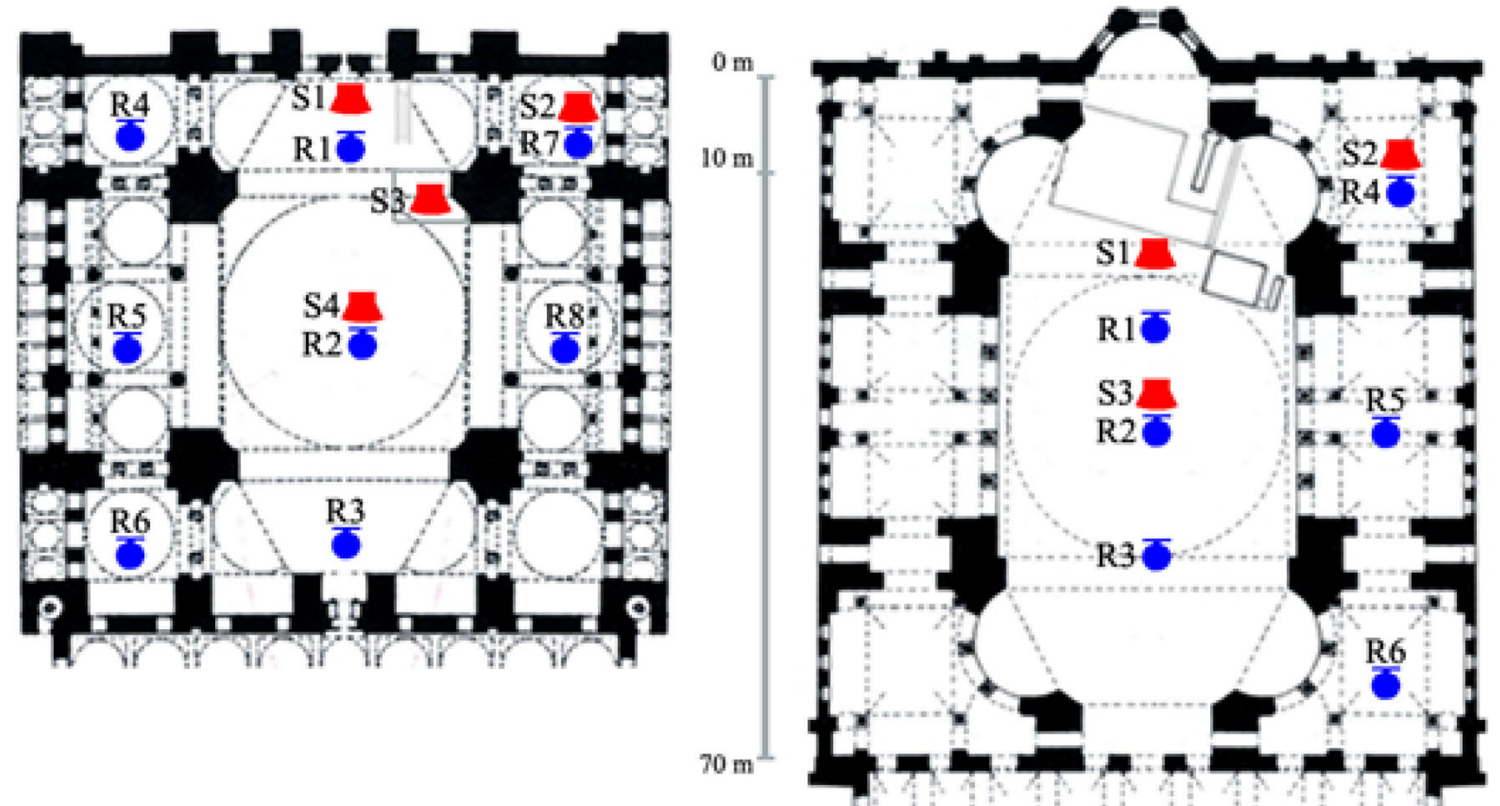

Fig. 4 Plan views showing sound source (in red) and receiver (in blue) locations during field tests in Süleymaniye Mosque (on the left) with acoustical volume of $100,000 \mathrm{~m}^{3}$ and in Hagia Sophia (on the right) with acoustical volume of $200,000 \mathrm{~m}^{3}$

the evaluation of multi-rate decay functions. In this process among a set of decay models, the most concise model providing the best fit to the decay function data enables to determine the parameters of the decay profile, namely the slopes of the decays and ordinate intercepts of those slopes [7].

Schroeder decay model is a generalized linear model consisting of linear combinations of a number of nonlinear terms or exponential terms. Bayesian model-based parameter estimation, describing Schroeder decay function, is used here to determine the parameters of the decay profile, namely "the slopes of decays" and "ordinate intercepts of those slopes." Schroeder decay functions are obtained through Schroeder backward integration. Parametric model describing Schroeder decay function is as follows;

$H_{S}\left(A, T, t_{i}\right)=A_{0}\left(t_{K}-t_{i}\right)+\sum_{j=1}^{S} A_{j}\left(\mathrm{e}^{\frac{-13.8 \times t_{i}}{T_{j}}}-\mathrm{e}^{\frac{-13.8 \times t_{K}}{T_{j}}}\right)$

where index $0 \leq i \leq K-1$.

Parametric model describing Schroeder decay function contains decay parameters of $A_{j}$ and $T_{j}$, where $A_{j}$ is the linear amplitude parameter and related to the level of individual exponential decay terms, $T_{j}$ is the decay time associated with the logarithmic decay slope of individual exponential decay terms, with $j=1,2, \ldots, S$, and $S$ is the maximum number of exponential decay terms, also termed as the decay order, $A_{0}$ $\left(t_{K}-t_{i}\right)$ is the noise term, and $t_{K}$ is the upper limit of integration, where the subscript $K$ is the total number of data points and $t_{i}$ with a lowercase subscript $i$ represents the discrete time variable [7].
The probable number of decay slopes in the energy decay is another question mark. Evaluating degrees of the curve fitting leads to over-parameterized models, since increased decay orders always improve curve fitting. As a scientifically rigorous solution, Xiang et al. [7] propose to evaluate the Bayesian evidence which automatically encapsulates the principle of parsimony and quantitatively implements Ockham's razor. Bayesian evidence prefers simpler models and penalizes over-fitting, so that it offers effective tools to conduct model selection and comparison going beyond traditional parameter estimation methods. The quantifier is defined to be Bayesian information criterion (BIC), which subtracts the penalty of over-parameterized models from the degree of the model fit to the data. Bayesian model selection rules out wrong models or competes unnecessary models. In the scope of the energy decay analysis among a set of decay models, the model yielding the largest BIC value is considered to be the most concise model providing the best fit to the decay function data and at the same time capturing the important exponentially decaying features evident in the data.

The term double-slope decay often vaguely characterizes decay functions which consist of a single or multiple decay components. Successful application of Bayesian analysis to the characterization of the Schroeder decay model of sound energy decays demonstrates that methods for characterizing non-exponential decays through visual inspection, through comparisons of linear-fits of logarithmic decay functions on an arbitrarily chosen portion or applying ratio-based quantifiers without considering their absolute values fail to capture 


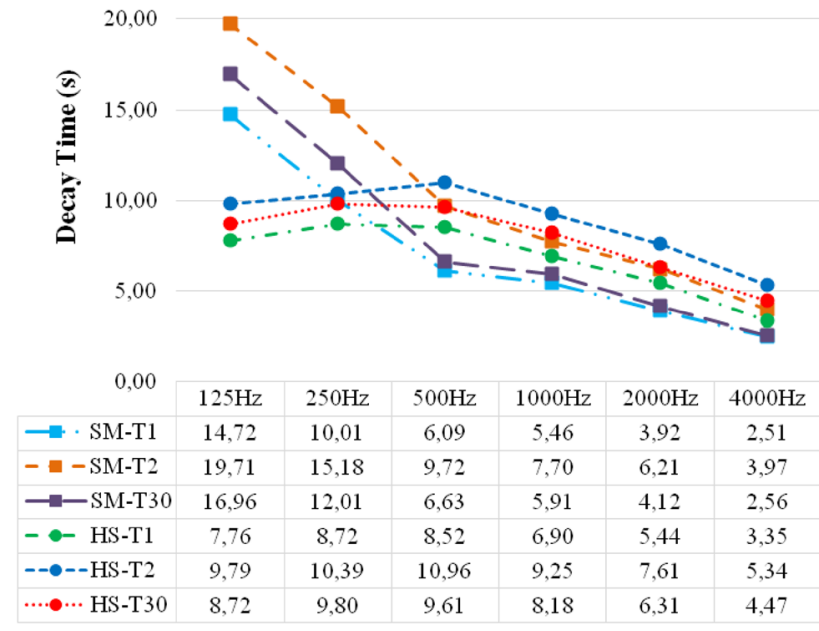

Fig. 5 Field measurement results of decay time (s) estimates averaged over source-receiver configurations; $T_{1}, T_{2}$ and $T_{30}$ values over $1 / 1$ octave bands in $\mathrm{Hz}$ for Süleymaniye Mosque (SM) and Hagia Sophia (HS)

important aspects of the system. Those quantifiers cannot generally provide a unique description for a non-exponential decay consisting of a linear combination of exponential decay functions and are scientifically questionable. For all that reason, Bayesian decay parameter estimation as described in this section has been found to be the most reliable analysis approach for coupling investigations on either architecturally coupled rooms or virtually coupled rooms in the form of a single space with specific geometric attributes as of multidomed mega-structures.

\section{Results and Discussion}

The joint interpretation of results over data obtained at field measurements is held to assess the sound fields of Süleymaniye Mosque and Hagia Sophia. The multiple decay rates are evaluated in relation to the interior surface material characteristics and geometrical features of these two structures. The reverberation time " $T_{30}$ " (Fig. 5) data obtained within the scope of this research provide a general insight for the acoustical conditions of the historic structures. The trend of the sound decay over frequency spectrum for Hagia Sophia field tests, considering $T_{30}$ values, is relatively much higher than those of Süleymaniye Mosque for $250 \mathrm{~Hz}$ and above. This result is expected due to the very large acoustical volume of Hagia Sophia which is twice the interior volume of Süleymaniye Mosque (Fig. 4).

Another significant aspect in relation to reverberation, aside from the sizes of interior volumes, is the interior finishing materials. In comparison with carpet-clad floor of Süleymaniye Mosque, marble-clad floor in Hagia Sophia is also very much effective in increasing reverberation times

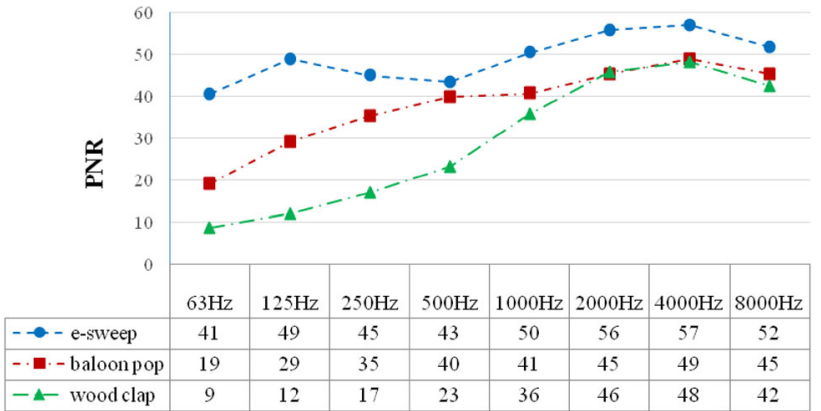

Fig. 6 Hagia Sophia PNR measurements in 1/1 octave bands in $\mathrm{Hz}$; comparison of e-sweep, balloon pop and wood clap source signals

$\left(T_{30}\right)$ specifically over mid-to high frequencies. In Hagia Sophia, mid- and low-frequency average of $T_{30}$ is around $9 \mathrm{~s}$ and high-frequency average is about $5 \mathrm{~s}$. This superb aural environment is considered to be unique and has a potential to provide multiple sound energy decay for specific locations. Further analyses are held within the framework of non-exponential energy decays in order to enlighten the architectural features and their contribution to room acoustics coupling.

One important factor in multi-slope decay parameter estimations is the background noise indicator that is peak signal-to-noise ratio (PNR). The reliability of PNR in field measurement tests is even more important for nonexponential sound energy decay analysis in comparison with spaces with exponential or single sound energy decay. The main reason is that the later decays are quantifiable only if the noise term is low enough, thus not corrupting the relevant data space within the analyzed frame of sound decay. Different source signals are tested in Hagia Sophia field measurements. The highest PNR values are checked over octave bands for electronically generated e-sweep signals, manual balloon pops and wood claps. Due to the long decay rates of Hagia Sophia, the e-sweep source signal lengths are kept around $20 \mathrm{~s}$. Although it is accepted that longer the sweep signals higher the PNR, it is also under discussion in terms of their liability to distortion. Thus, within the process of impulse response selection initially the PNR values are compared for e-sweep, balloon pop and wood clap. Another reason for testing these different source signals is to relatively test the adequacy of e-sweep for both low-frequency and high-frequency range analysis.

The results indicate that Hagia Sophia is too large to be excited with either balloon pop or wood clap in overall frequency spectrum. Using alternative excitation signals such as wood claps or popping of a balloon has not provided the sufficient peak-to-noise ratio, and neither of those source signals are perfectly omni-directional. As can be observed from Fig. 6, providing higher PNR, e-sweep is more reliable to be used in multi-slope investigations in comparison with balloon pop and wood clap both in low- and high-frequency ranges. 
Deviation is mostly at lower octaves, where wood clap has the lowest PNR values in comparison with both balloon pop and e-sweep. High octaves are much identical for balloon pop and wood clap, where e-sweep still has a significant raise, almost $10 \mathrm{~dB}$ higher in peak-to-noise ratios. Briefly, e-sweep excitation has the highest PNR and provides the most dependable data even in high-frequency range in comparison with other source signals. Thus, in decay parameter estimations, only the e-sweep-generated impulses are analyzed.

The main highlight of this study is that the sound energy decay patterns do not indicate a classical single or exponential curve in the case structures. So, the classical decay time metrics as of $T_{20}, T_{30}$ and EDT may not be adequate to describe their particular sound fields. Therefore, the multiple slope decay parameters over impulse responses obtained in field measurements are analyzed with Bayesian probabilistic inference method [7]. The estimated number of decay slopes over octave bands at measured source and receiver configurations for Süleymaniye Mosque and Hagia Sophia is presented in Table 1. Distribution maps showing the average numbers of decay slopes determined at measured receiver positions are given in Fig. 7. Detailed analysis of decay rates $\left(T_{i}\right)$ and decay levels $\left(A_{i}\right)$, as acoustical coupling indicators, selected for some specific locations and octave bands is presented in Table 2. The average $T_{1}$ and $T_{2}$ values in overall test locations are plotted in Fig. 5 together with measured $T_{30}$ values. From Fig. 6, it can clearly be observed that $T_{30}$ estimates are mostly in between the other two decay rates $\left(T_{1}\right.$ and $T_{2}$ ).

In overall test positions, Süleymaniye Mosque provides greater number of decay slopes, mostly double slopes, in comparison with Hagia Sophia. Conversely, for certain source and receiver configuration, as of $S_{2} R_{5}$ and $S_{2} R_{6}$, the triple slope occurrence in Hagia Sophia is drastically higher than its occurrence in Süleymaniye Mosque (Table 1). This instance is due to those specific measurement locations, which are both at side aisles under gallery. In those specific locations, the sound source and receiver are together positioned at virtually separated zone (side aisle) with lower natural reverberation, as of in a typical coupled space scenario. Here, the coupled space or secondary volume which provides energy feedback is the main nave underneath the central dome axis of Hagia Sophia. Similarly, the convex curve formation due to coupling between subspaces has been detected in some previous researches [18-22]. The occurrence of multiple sound energy decay in Süleymaniye Mosque can be explained by the central dome as an energy accumulation center versus the carpeted floor as a sound attenuation surface (Table 1 and Fig. 7). Geometrical attributes of the structure, interior materials' absorption characteristics and their distribution within the structure augment the possibility of multiple sound energy decay formation in Süleymaniye Mosque [31, 32].
In overall, maximum number of decay rates are observed at $250 \mathrm{~Hz}$ for both structures. Double slope is the dominant number of decay slope. Triple slopes are mostly observed at low octave bands. This may be a result of very long decay rates in low frequencies, as a reason of sound arriving late from different virtual subspaces. Number of slopes are slightly higher underneath side corner domes of Süleymaniye Mosque. This is mostly due to the better separation of this corner volume from the main space. For Süleymaniye Mosque, number of slopes are slightly higher for sources in front of mihrab and underneath central dome. However, considering the number of measurements taken in permitted time, statistically no significant deviation in average number of slopes per source locations can be stated. Süleymaniye Mosque has a much even distribution in comparison with Hagia Sophia. In Süleymaniye Mosque, side apertures (arches) are larger and the space still behaves as of a single volume, whereas in Hagia Sophia, the smaller openings of side arcades provide more defined coupled side galleries. This can be clearly observed when both source and receiver are located underneath side aisles of Hagia Sophia.

In the process of data analysis, all data are compared in light of model penalization framework of Bayesian estimation in getting the best data fit and probable decay slope (Table 2). BIC values in Neper indicate the higher degree of one model in comparison with another. For instance, in the case of Hagia Sophia for measurement position $\mathrm{S}_{2} \mathrm{R}_{6}$ filtered for $500 \mathrm{~Hz}$, the results designate a higher value of triple slope decay of BIC in comparison with the same model tested for the double-slope decay. For that reason, these data imply a triple slope. Similarly, in the case of Süleymaniye Mosque for measurement position $\mathrm{S}_{1} \mathrm{R}_{4}$ filtered for $1000 \mathrm{~Hz}$, the results designate a higher value of double-slope decay of BIC in comparison with the same model tested for the single slope decay. Accordingly, the data are considered as a double-slope case.

The detailed multiple sound energy decay outputs are illustrated in Fig. 8 for selected positions of $S_{3} R_{7}$, filtered for $250 \mathrm{~Hz}$ in Süleymaniye Mosque and $S_{2} R_{6}$, filtered for $500 \mathrm{~Hz}$ in Hagia Sophia. Turning points indicate the position where one decay slope intersects with the other one and are important signifiers for the return of energy decay [7]. The early (1st decay curve) and late (2nd and 3rd decay curve) energy decays are indicators of basic subjective acoustical parameters.

The results obtained out of field measured data in this study prove the presence of multiple slopes in existing historic sacred structures; Süleymaniye Mosque and Hagia Sophia. As illustrated on the decay slopes of Fig. 8 and detailed in Table 2, the later decay $\left(T_{2}, A_{2}\right.$ and $\left.T_{3}, A_{3}\right)$ contributes to the subjective reverberance. Ideally, the early decay $\left(T_{1}, A_{1}\right)$ would contribute to the subjective clarity. However, within this mega-structure, it is hard to mention 


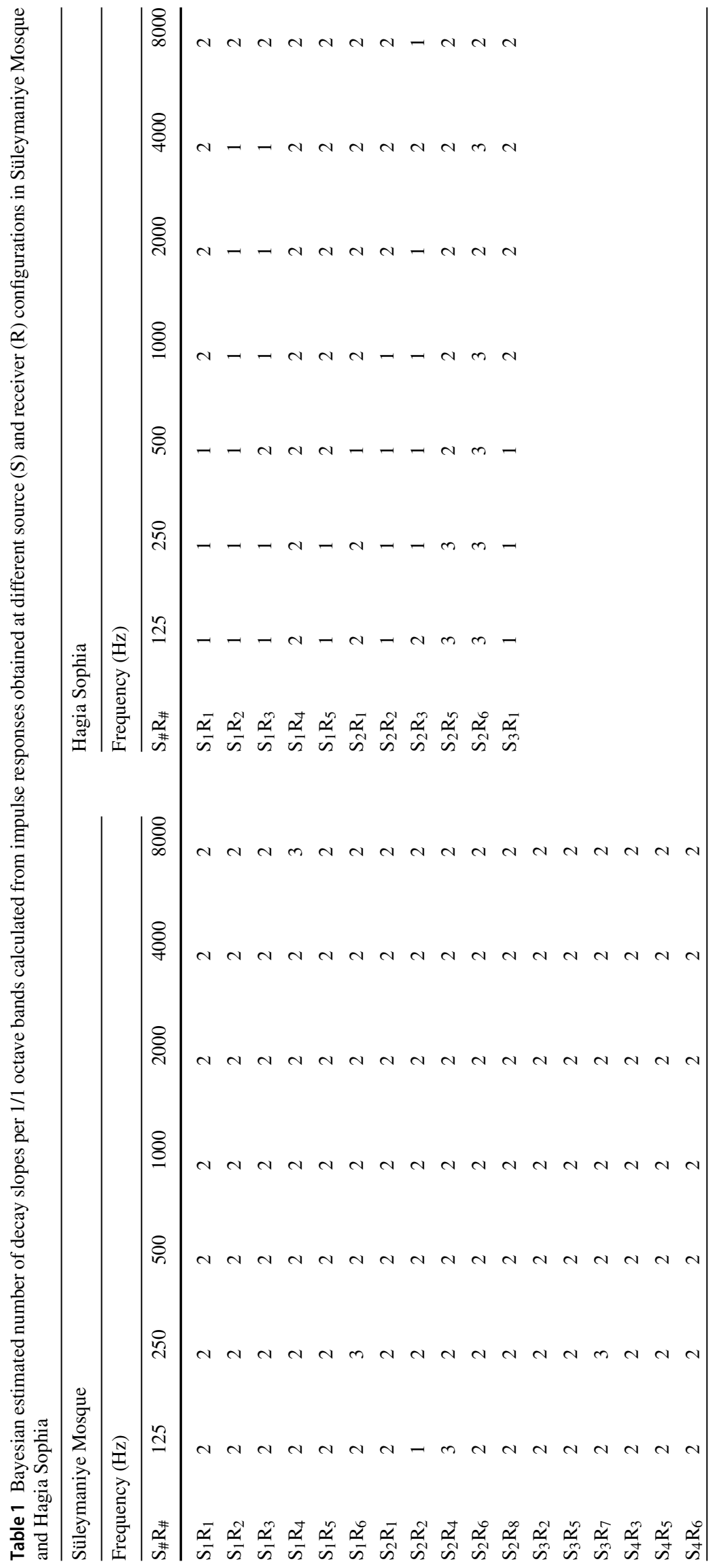



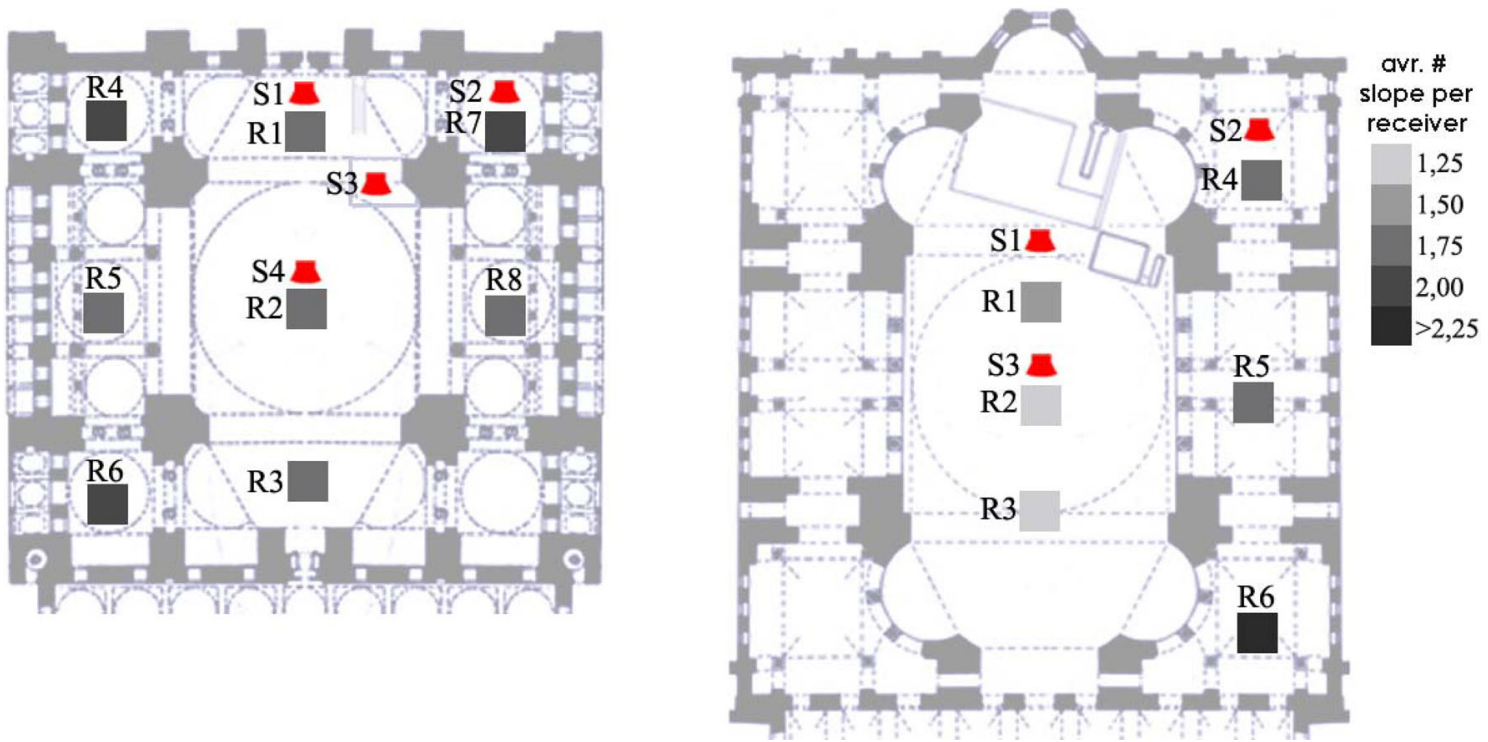

Fig. 7 Distribution maps showing average number of decay slopes over receiver positions in Süleymaniye Mosque and Hagia Sophia

Table 2 Decay parameters (decay levels $-A_{i}$ and decay times $-T_{i}$ ) for impulse responses collected in Süleymaniye Mosque at $\mathrm{S}_{3} \mathrm{R}_{7}$ (for $250 \mathrm{~Hz}$ ) and at $\mathrm{S}_{1} \mathrm{R}_{4}$ (for $1000 \mathrm{~Hz}$ ) and in Hagia Sophia at $\mathrm{S}_{2} \mathrm{R}_{6}$ (for $500 \mathrm{~Hz}$ ) and at $\mathrm{S}_{1} \mathrm{R}_{5}$ (for $2000 \mathrm{~Hz}$ )

\begin{tabular}{lllll}
\hline Decay parameters & $\begin{array}{l}\text { Süleymaniye } \\
\mathrm{S}_{3} \mathrm{R}_{7}, 250 \mathrm{~Hz}\end{array}$ & $\begin{array}{l}\text { Hagia Sophia } \\
\mathrm{S}_{2} \mathrm{R}_{6}, 500 \mathrm{~Hz}\end{array}$ & $\begin{array}{l}\text { Süleymaniye } \\
\mathrm{S}_{1} \mathrm{R}_{4}, 1000 \mathrm{~Hz}\end{array}$ & $\begin{array}{l}\text { Hagia Sophia } \\
\mathrm{S}_{1} \mathrm{R}_{5}, 2000 \mathrm{~Hz}\end{array}$ \\
\hline $\mathrm{A}_{0}(\mathrm{~dB})$ & -86 & -79 & -84 & -85 \\
$\mathrm{~A}_{1}(\mathrm{~dB})$ & -7.8 & -7.3 & -5.5 & -6.7 \\
$\mathrm{~T}_{1}(\mathrm{~s})$ & 8.9 & 6.7 & 5.3 & 5.4 \\
$\mathrm{~A}_{2}(\mathrm{~dB})$ & -9.0 & -10.4 & -16.0 & -10.0 \\
$\mathrm{~T}_{2}(\mathrm{~s})$ & 13.5 & 10.3 & 8.1 & 7.6 \\
$\mathrm{~A}_{3}(\mathrm{~dB})$ & -15.1 & -14.8 & - & - \\
$\mathrm{T}_{3}(\mathrm{~s})$ & 17.1 & 13.3 & - & - \\
$\mathrm{BIC}(\mathrm{Neper})$ & $15,829(3$ slopes $)$ & $20,882(3$ slopes $)$ & $12,343(2$ slopes $)$ & $30,962(2$ slopes $)$ \\
$\mathrm{BIC}_{(\mathrm{Neper})}$ & $9700(2$ slopes $)$ & $15,863(2$ slopes $)$ & $6263(1$ slope $)$ & $21,124(1$ slope $)$ \\
$\mathrm{BIC}_{3,2} / 2,1$ (Neper) & 6129 & 5019 & 6080 & 9838 \\
\hline
\end{tabular}

about a clarity in classical terms that satisfies criteria for even liturgical music. Although the early decay rates are lower than later decays, they are still much higher than conventional limits, due to excessive volumes. For that reason, rather than mentioning subjective clarity it may better be stated that the multiple sound energy decays in these two sacred spaces provide a rich acoustical environment, which eventually augment their spiritual aspects.

\section{Conclusions}

Within the context of this study, sound fields within Süleymaniye Mosque and Hagia Sophia, two major monuments of İstanbul World Heritage Site, are analyzed. Süleymaniye Mosque with a square plan sheltered with multi-domed upper structure provides a single-space definition. Hagia Sophia's basilican plan sheltered by multiple domes also defines a single acoustical space. An interesting outcome of the study is that despite having single-space volumes both structures feature non-exponential energy decay in their sound fields. Distribution of absorptive and reflective interior surfaces and geometric attributes of these two mega-structures provide sound energy flows inside, among sub-volumes (Fig. 9). All these geometric and material attributes cause sound energy concentration and fragmentation within main and subspaces that augment the non-exponential or multiple sound energy decay formation.

Main differences between Hagia Sophia and Süleymaniye Mosque are: (i) Hagia Sophia has a larger volume, almost twice, in comparison with Süleymaniye Mosque; and (ii) Hagia Sophia has a marble-clad sound reflective floor surface, while Süleymaniye Mosque has carpet-clad sound absorptive one. Due to volumetric differences, dimensional proportions and variable sound absorption characteristics of interior surfaces, Süleymaniye Mosque, have expectedly 


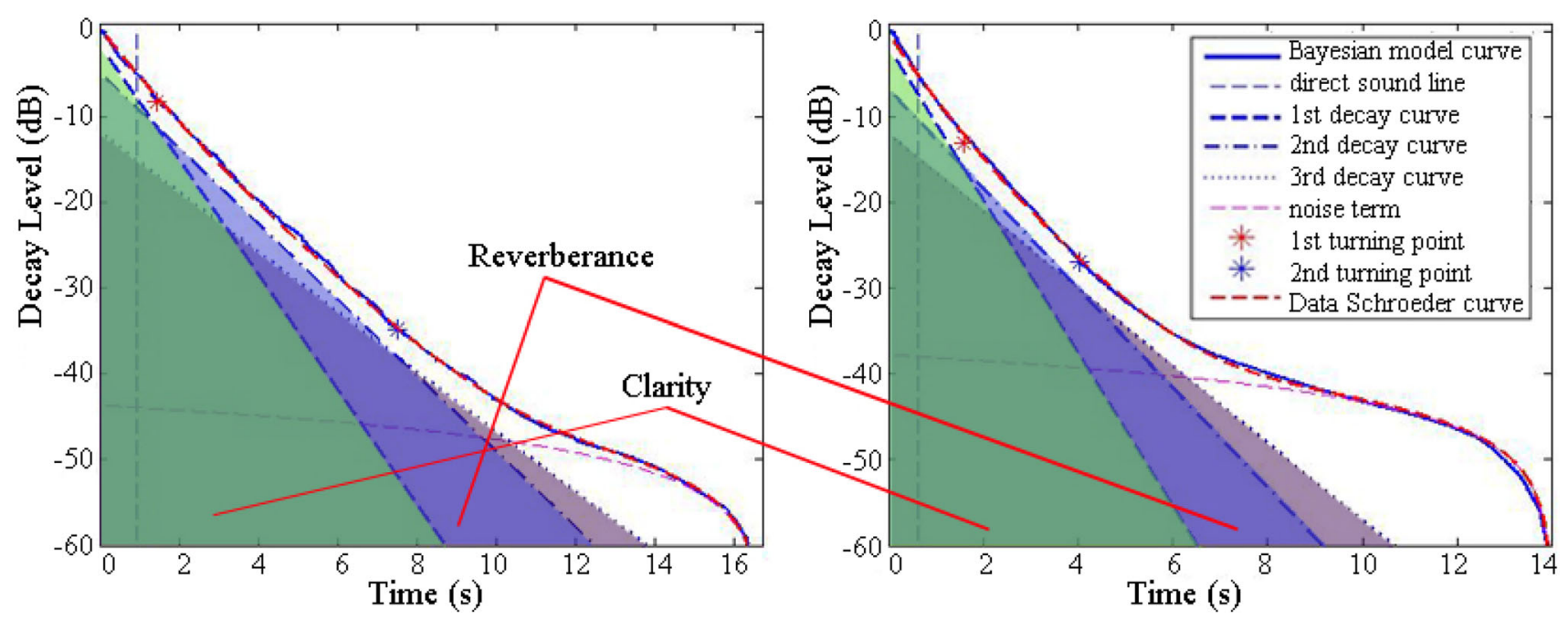

Fig. 8 Schroeder curve and the model curve derived from impulse responses collected in Süleymaniye Mosque at $\mathrm{S}_{3} \mathrm{R}_{7}$, filtered for $250 \mathrm{~Hz}$ (on the left) and in Hagia Sophia at $S_{2} R_{6}$, filtered for $500 \mathrm{~Hz}$ (on the right); three decomposed decay slope lines and two turning points; subjective clarity and reverberance conceptual indications
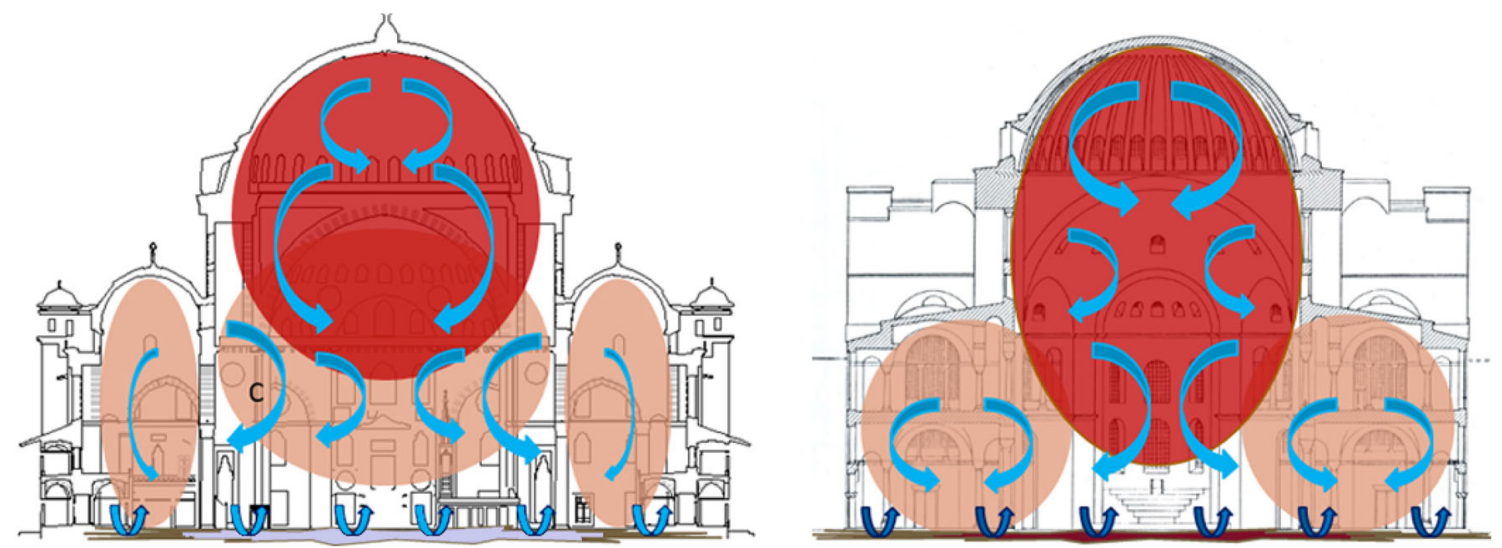

Fig. 9 Süleymaniye Mosques' conceptual section view of sound energy flows (on the left) and Hagia Sophia's conceptual section view of sound energy flows (on the right)

lower decay rates in overall frequency range in comparison with Hagia Sophia (Fig. 5). Note that, higher reverberance inside Hagia Sophia is much suitable for its original function, where liturgical music can be performed, in comparison with Süleymaniye Mosque, where music is not practiced but only ritual sermons and instead, intelligibility of praying orders and sermon, are much significant. However, still the decay rates are much higher than recommended limits for both structures under unoccupied conditions.

In terms of multiple decay formations, the absorption introduced by carpet floor finish in Süleymaniye Mosque versus a reflective upper structure provides an un-diffused sound field. Consequently, the sound energy density fragmentation in Süleymaniye Mosque is much obvious in comparison with Hagia Sophia due to relatively diffused sound field of Hagia Sophia. Thus, the overall number of decay slopes is greater in Süleymaniye Mosque than in Hagia Sophia. On the other hand, the span of arches which separate the main prayer hall from side aisles in Süleymaniye Mosque and the span of arches connecting the side galleries to the central nave in Hagia Sophia differ in dimension. Due to the larger span of arches in Süleymaniye Mosque, the side aisles behind those major arches supporting the central dome are not restricted as much as arcades separating side aisles of Hagia Sophia (Figs. 1, 2). The smaller arches of Hagia Sophia with a basilican plan layout create much defined coupling apertures, and thus, maximum amount of decay rates, specifically triple slopes, occur underneath its side aisle galleries (Table 1).

The reliability of data in terms of peak signal-to-noise ratio (PNR) is highly significant in such a study that investigates multi-slope decay occurrence. Thus, different sound signals are tested in order to get the best data for Bayesian analysis. To summarize, balloon pop has better PNR values than wood clap, but still unsatisfactory specifically for lower octaves. E- 
sweep excitation has the highest PNR and provides the most dependable data even in high-frequency range in comparison with other source signals (Fig. 6).

The unusual sensation (hearing) of sound in such monumental sacred spaces may be explained by overlapping decay curves and their acoustical outcomes. The identification of multiple decay rates in such monumental sacred spaces is significant to point out their potential for providing individual spiritual effects in relation to perception of sound within such enclosures. To design for a proper acoustic response in those historic structures for their original uses is a troublesome work and very challenging, especially in the dates of construction. Intentionally or not, the occurrence of multiple slopes in such sacred spaces had actually enriched the quality of their sound field. This might be one of the reasons for such structures, as of gothic cathedrals, to be recognized or acknowledged by their acoustics.

To conclude, in this research the acoustical metrics or indicators to define the sound fields of sacred mega-structures are revisited. It is concluded that acoustical metrics that are developed for single slope/exponential sound decays as of $T_{20}, T_{30}$ or EDT are not adequate to understand the decay characteristics within such spaces especially those with multi-domed upper shell typology. For understanding the sound fields of such monumental spaces, multiple sound energy decay estimation methods as of Bayesian formulation should be utilized. That allows identification of the turning points within multi-slope energy decays as well as determination of decay times $\left(T_{x}\right)$ and decay levels $\left(A_{x}\right)$, socalled decay parameters. Quantifying the degree of subjective effects and relating them to objective decay parameters of multi-slope energy decays in sacred spaces is another research problem and necessitates further investigations on psycho-acoustic test responses of users. The outcomes raise the need for future research on re-formulation of "reverberation time" definition and calculation methods in the case of rooms with multiple slope sound energy decays, as of in monumental sacred spaces.

Acknowledgements The authors would like to express their gratitude to the General Directorate of Pious Foundations (Vakıflar Genel Müdürlügüi) for providing measured drawings of Süleymaniye Mosque and for giving permissions on field measurements. Turkish Ministry of Culture and Tourism, and General Directorate of Turkish Cultural Heritage and Museums are gratefully acknowledged for their permissions on Hagia Sophia field measurements.

\section{References}

1. Necipoglu, G.: The Age of Sinan, Architectural culture in the Ottoman Empire. Princeton University Press, New Jersey (2005)

2. Kuban, D.: Ottoman Architecture. Antique Club, Woodbridge (2010)
3. Weitze, C.A., Rindel, J.H., Christensen, C.L., Gade, A.C.: The Acoustical History of Hagia Sophia Revived through Computer Simulation. Forum Acusticum, Seville (2002)

4. Su Gul, Z., Caliskan, M., Tavukcuoglu, A.: On the acoustics of Süleymaniye Mosque: from past to present. Megaron 9(3), 201-216 (2014)

5. Topaktaş, L.: Acoustical properties of classical ottoman mosques, simulation and measurements. Unpublished Ph.D. thesis. Graduate School of Natural and Applied Sciences, Middle East Technical University, Ankara, Turkey (2003)

6. CAHRISMA: Acoustical properties of domed spaces and optimum acoustical conditions for Domed Mosques. Combined deliverable (D29-D34-D35), project number: ICA3-CT-1999-00007. Y1ldız Technical University, İstanbul (2003)

7. Xiang, N., Goggans, P.M., Jasa, T., Robinson, P.: Bayesian characterization of multiple-slope sound energy decays in coupledvolume systems. J. Acoust. Soc. Am. 129(2), 741-752 (2011)

8. Suárez, R., Alonso, A., Sendra, J.J.: Intangible cultural heritage: the sound of the Romanesque cathedral of Santiago de Compostela. J. Cultural Heritage 16(2), 239-243 (2015)

9. Luigi, E., Martellotta, F.: Acoustics as a cultural heritage: the case of orthodox churches and of the "Russian church" in Bari. J. Cult. Herit. 16(6), 912-917 (2015)

10. Abdou, A.A.: Measurement of acoustical characteristics of mosques in Saudi Arabia. J. Acoust. Soc. Am. 113(3), 1505-1517 (2003)

11. Sü Gül, Z., Çalışkan, M.: Impact of design decisions on acoustical comfort parameters: case study of Doğramacızade Ali Paşa Mosque. App. Acoust. 74, 834-844 (2013)

12. Kleiner, M., Klepper, D.L., Torres, R.R.: Worship Space Acoustics. J. Ross Publishing, Fort Lauderdale (2010)

13. Fausti, P., Pompoli, R., Prodi, N.: Comparing the acoustics of mosques and byzantine churches. In: CIPA XIXth International Symposium, Antalya, Turkey (2003)

14. Carvalho, A.P., Monteiro, C.G.: Comparison of the acoustics of mosques and catholic churches. In: ICSV16, Kraków, Poland (2009)

15. Eyring, C.F.: Reverberation time measurements in coupled rooms. J. Acoust. Soc. Am. 3(2), 181-206 (1931)

16. Cremer, L., Müller, H.A. (eds.): Coupled rooms. In: Principles and Applications of Room Acoustics (Schultz, T., Trans.), vol. 1, pp. 261-292. Elsevier, London (1978)

17. Summers, J.E., Torres, R.R., Shimizu, Y.: Statistical-acoustics models of energy decay in systems of coupled rooms and their relation to geometrical acoustics. J. Acoust. Soc. Am. 116(2), 958-969 (2004)

18. Anderson, J.S., Anderson, M.B.: Acoustic coupling effects in St Paul's Cathedral, London. J. Sound Vib. 236(2), 209-225 (2000)

19. Suárez, R., Sendra, J.J., Navarro, J., León, A.L.: The acoustics of the Cathedral-Mosque of Córdoba, proposals for architectural intervention. Acta Acust. United Acust. 90, 362-375 (2004)

20. Martellotta, F.: Identifying acoustical coupling by measurements and prediction-models for St. Peter's Basilica in Rome. J. Acoust. Soc. Am. 126(3), 1175-1186 (2009)

21. Magrini, A., Magnani, L.: Models of the influence of coupled spaces in Christian churches. Build. Acoust. 12(2), 115-139 (2005)

22. Martellotta, F., Alvarez-Morales, L., Giron, S., Zamarreno, T.: An investigation of multi-rate sound decay under strongly non-diffuse conditions: the crypt of the Cathedral of Cadiz. J. Sound Vib. 421, 261-274 (2018)

23. Kuban, D.A.: Symbol of Ottoman Architecture: The Süleymaniye. Ottoman Architecture, pp. 277-294. Antique Collectors' Club, Suffolk (2010)

24. Barkan, L.O.: Süleymaniye Camii ve İmareti İnşaatı (1550-1557), vol. 1-2. Türk Tarih Kurumu Matbaası, Ankara (1972) 
25. Necipoğlu-Kafadar, G.: The Süleymaniye Complex in İstanbul: an interpretation. Muqarnas 3, 92-117 (1985)

26. Kahler, H., Mango, C.: Hagia Sophia, p. 250. Frederick A. Praeger, New York (1967)

27. Klenbauer, W.E., White, A., Matthews, H.: Hagia Sophia. Scala Publishers, London (2004)

28. Xiang, N., Goggans, P.M.: Evaluation of decay times in coupled spaces: Bayesian parameter estimation. J. Acoust. Soc. Am. 110(3), 1415-1424 (2001)

29. Xiang, N., Goggans, P.M.: Evaluation of decay times in coupled spaces: Bayesian decay model selection. J. Acoust. Soc. Am. 113, 2685-2697 (2003)
30. Xiang, N., Goggans, P.M., Jasa, T., Kleiner, M.: Evaluation of decay times in coupled spaces: Reliability analysis of Bayesian decay time estimation. J. Acoust. Soc. Am. 117, 3707-3715 (2005)

31. Su Gul, Z., Xiang, N., Caliskan, M.: Investigations on sound energy decays and flows in a monumental mosque. J. Acoust. Soc. Am. 140(1), 344-355 (2016)

32. Su Gul, Z., Xiang, N., Caliskan, M.: Diffusion equation based finite element modeling of a monumental worship space. J. Comput. Acoust. 25(4), 1-16 (2017) 